\title{
- Apoio Matricial em Unidades de Saúde da Família: experimentando inovações em saúde mental'
}

\section{Matrix Support in Family Health Units: experiencing innovations in mental health}

\author{
Magda Dimenstein \\ Doutora em Saúde Mental. Professora do Programa de Pós-Gra- \\ duação em Psicologia da Universidade Federal do Rio Grande \\ do Norte. \\ Endereço: UFRN, CCHLA, Dept. de Psicologia, Campus Universitário, \\ Lagoa Nova, CEP 59078-970, Natal, RN, Brasil. \\ E-mail: magdaळufrnet.br

\section{Ana Kalliny Severo} \\ Mestranda do Programa de Pós-Graduação em Psicologia da \\ UFRN. Bolsista CNPq. \\ Endereço: Rua Pintor Rodolfo de Amoedo, 528, Pitimbu, CEP 59069- \\ 150, Natal, RN, Brasil. \\ E-mail: kallinyseveroळyahoo.com.br

\section{Monique Brito} \\ Psicóloga pela UFRN. Bolsista PIBIC/CNPq. \\ Endereço: Rua Madre Teresa de Calcutá, 2000, casa 115, Nova \\ Parnamirim, CEP 59150-000, Natal, RN, Brasil. \\ E-mail: monique_brito®yahoo.com.br \\ Ana Lícia Pimenta \\ Psicóloga. \\ Endereço: UNP, Dept. de Psicologia, Campos Salgado Filho, 1610, \\ Lagoa Nova, CEP 59056-000, Natal, RN, Brasil. \\ E-mail: analiciasoaresळhotmail.com
}

\section{Vanessa Medeiros}

Mestre em Psicologia pelo PPGPsi/UFRN. Bolsista de Apoio Técnico/CNPq.

Endereço: Av. Sen. Salgado Filho, 2990/208, Candelária, CEP 59066-800, Natal, RN, Brasil.

E-mail: vanemedeirosळyahoo.com.br

\section{Edilane Bezerra}

Mestre em Psicologia.

Endereço: UFRN, CCHLA, Dept. de Psicologia, Campus Universitário, Lagoa Nova, CEP 59078-970, Natal, RN, Brasil.

E-mail: edilane.bezerraळig.com.br

I Pesquisa financiada com recursos do CNPq - Conselho Nacional de Desenvolvimento Científico e Tecnológico.

\section{Resumo}

A Reforma Psiquiátrica busca superar as intervenções tradicionalmente hospitalocêntricas e medicalizantes em relação à "loucura”. Para isso, visa implantar estratégias de cuidado territoriais e integrais, ancorados em novos saberes e valores culturais. Nessa perspectiva, o Apoio Matricial surge como proposta para articular os cuidados em saúde mental à Atenção Básica. Este trabalho objetiva discutir a perspectiva de técnicos de Unidades de Saúde da Família (USF) do município de Natal, RN, acerca dessa proposta. Foram realizadas entrevistas com oito técnicos da USF do Distrito Sanitário Leste da cidade. A partir dos resultados observamos que não há clareza acerca da proposta de Apoio Matricial (AM) e há uma forte demanda cotidiana de saúde mental não acolhida, pois os entrevistados não se sentem capacitados para tal e indicam a necessidade de apoio e instrumentalização nesse campo. Além disso, as possibilidades de referenciamento são pequenas em função da precariedade da rede de serviços substitutivos e destes com a rede do Sistema Único de Saúde (SUS) como um todo. 0 trabalho compartilhado com o Centro de Atenção Psicossocial (CAPS) é ainda uma promessa.

Palavras-chave: Reforma psiquiátrica; Saúde mental; Programa de saúde da família; Apoio matricial. 


\section{Abstract}

The Psychiatric Reform aims to overcome the traditional interventions concerning "madness", which are hospital-centered and medicine-based. To achieve this, its objective is to implement territorial and integral care strategies, supported by new knowledge and cultural values. In this perspective, the Matrix Support emerges as a proposal to articulate mental healthcare with Primary Care. This study aims to discuss the perspective of technicians from Unidades de Saúde da Família (USF - Family Health Units) of the municipality of Natal, state of Rio Grande do Norte, concerning this proposal. Interviews with eight technicians of the USF of the East Sanitary District of the city were conducted. Based on the results, we observed that the proposal for Matrix Support is not clear and there is a strong daily mental health demand that has not been met, as the interviewees do not feel qualified to perform this service and indicate the need of support and training in this field. In addition, the referral possibilities are limited, due to the precariousness of the network of substitutive services and of these with the network of Sistema Único de Saúde (SUS - National Health System) as a whole. Shared work with Centro de Atenção Psicossocial (CAPS - Center for Psychosocial Care) is still a promise.

Keywords: Psychiatric Reform; Mental Health; Family Health Program; Matrix Support.

\section{Introdução}

A Reforma Psiquiátrica Brasileira tem como característica a tentativa de superação do cenário histórico de desassistência e maus-tratos no campo da saúde mental e a construção de novos espaços de intervenção assistenciais, políticos e jurídicos em relação à "loucura”. Atualmente o Ministério da Saúde vê a Reforma Psiquiátrica como:

Um conjunto de transformações de práticas, saberes, valores culturais e sociais em torno do "louco" e da "loucura", mas especialmente em torno das políticas públicas para lidar com a questão. Trata-se de um processo político e social complexo, composto de atores, instituições e forças de diferentes origens, e que incide em territórios diversos, nos governos federal, estadual e municipal, nas universidades, no mercado dos serviços de saúde, nos conselhos profissionais, nas associações de pessoas com transtornos mentais e de seus familiares, nos movimentos sociais, e nos territórios do imaginário social e da opinião pública (Brasil, 2007, p. 63).

A Reforma Psiquiátrica aponta para a superação do modelo hospitalocêntrico no atendimento do transtorno mental, tendo em vista um cuidado que não afaste o portador do seu espaço social. Desse modo, a atenção básica, no campo da saúde pública brasileira, constitui-se em um espaço privilegiado de intervenção mostrando-se como uma estratégia significativa para traçar ações focadas no eixo territorial. O Programa de Saúde da Família (PSF), criado em 1994, destaca-se nesse contexto.

A diretriz conceitual do Ministério da Saúde sobre Atenção Básica e sobre o Programa de Saúde da Família indica que a expansão e a qualificação da atenção básica, organizadas pela estratégia Saúde da Família, compõem parte do conjunto de prioridades políticas, devendo essa concepção superar a antiga proposição de caráter exclusivamente centrado na doença, desenvolvendo-se por meio de práticas gerenciais e sanitárias, democráticas e participativas, sob a forma de trabalho em equipe, dirigidas às populações de territórios delimitados, pelos quais assumem responsabilidade. Essa perspectiva é antagônica ao modelo de atendimento centrado nos especialismos, que adota uma perspectiva de saúde fragmentada, distante da concretude da vida dos sujeitos, o qual tem sido 
intensamente questionado desde a década de 1980, com o Movimento da Reforma Sanitária.

Sabe-se que foi após a Segunda Guerra Mundial, com o surgimento do Estado de Bem-estar Social, que se evidenciou uma maior preocupação com as políticas sociais. Nesse contexto, a instituição manicomial foi problematizada como um lugar de produção de doença mental. Segundo Rosa (2003), o processo de Reforma Psiquiátrica passou por períodos distintos anteriores: os movimentos de crítica à estrutura asilar, considerada patologizante e cronificadora, que buscavam a reestruturação do hospital, sendo ele ainda concebido como um lugar de cura. Entretanto, é a Psiquiatria Democrática Italiana, através de Franco Basaglia, que expressa a ruptura das propostas de reformas apresentadas até então, por questionar a exclusão imposta pela função social da psiquiatria, do asilo e dos técnicos, indo além da análise de natureza médico-psicológica da "loucura”. Na década de 1980, inspirados na Reforma Italiana, a Reforma Psiquiátrica Brasileira tentou efetivar uma ruptura paradigmática. Cenário político de críticas e de implantação do SUS, fruto do movimento da Reforma Sanitária, a luta antimanicomial segue até hoje criticando as práticas excludentes, segregadoras, centradas no manicômio e priorizando intervenções mais complexas centradas na territorialidade.

A partir dessas críticas, o ato de cuidar implica em compreender a saúde de maneira global, intrincada ao modo de vida das pessoas. A saúde, sendo percebida como recurso para a produção de vida diária dos usuários, exige novos modos de tratar e de acolher o sujeito em sofrimento, principalmente o portador de transtorno mental, na sua vida diária e em seu espaço comunitário. Desse modo, a unidade básica tornou-se fundamental para esse tipo de acompanhamento. É nessa perspectiva que a saúde mental deve ser entendida, como um campo de intervenção prioritário também para as equipes do Programa de Saúde da Família (PSF), pois têm a potencialidade de: atuar não só na unidade, mas no espaço social onde a comunidade vive e circula; estabelecer vínculos de compromisso e corresponsabilidade com a população; trabalhar norteados por uma perspectiva ampliada sobre os modos de vida, de saúde e doença articulada ao contexto familiar e cultural; intervir sobre fatores de risco aos quais a comunidade está exposta - sendo os transtornos mentais um dos mais evidentes - por meio de parcerias estabelecidas com diferentes segmentos sociais e institucionais, visando interferir em situações que transcendem a especificidade do setor saúde e têm efeitos determinantes sobre as condições de vida e saúde dos indivíduosfamílias-comunidade.

Segundo o Ministério de Saúde (Brasil, 2005), os principais desafios da Reforma Psiquiátrica é que $3 \%$ da população necessita de cuidados contínuos em saúde mental, em função de transtornos severos e persistentes, o que exige uma rede de assistência densa, diversificada e efetiva. Somado a isso, aproximadamente de $10 \%$ a $12 \%$ da população não sofre transtornos severos, mas precisam de cuidados em saúde mental, na forma de consulta médico-psicológica, aconselhamento, grupos de orientação e outras formas de abordagem. Isso, consequentemente demanda uma rede assistencial ampla e integrada. Além disso, a Organização Mundial da Saúde (OMS) vem registrando uma preocupação gradativa nos últimos anos com as chamadas doenças crônicas no mundo inteiro, dentre as quais estão os transtornos mentais:

Os problemas de saúde mental ocupam cinco posições no ranking das 10 principais causas de incapacidade no mundo, totalizando $12 \%$ da carga global de doenças. Atualmente, mais de $400 \mathrm{mi}-$ lhões de pessoas são acometidas por distúrbios mentais ou comportamentais e, em virtude do envelhecimento populacional e do agravamento dos problemas sociais, há probabilidade de o número de diagnósticos ser ainda maior. Esse progressivo aumento na carga de doenças irá gerar um custo substancial em termos de sofrimento, incapacidade e perda econômica (OMS, 2003, p. 19).

Segundo o relatório "Cuidados inovadores para condições crônicas: componentes estruturais de ação":

As doenças crônicas apresentam um ponto em comum: elas persistem e necessitam de certo nível de cuidados permanentes. Além disso, as condições crônicas compartilham algumas características preocupantes: estão aumentando no mundo e nenhum país está imune ao impacto causado por elas; representam um sério desafio para os atuais sistemas de saúde no tocante à eficiência e efetividade e desafiam nossas capacidades em organizar sistemas que supram as demandas iminentes; causam sérias conseqüências econômicas e sociais em 
todas as regiões e ameaçam os recursos da saúde em cada país e podem ser minimizadas somente quando os líderes do governo e da saúde adotarem mudanças e inovações (OMS, 2003, p. 15).

Esse documento aponta, ainda, que os distúrbios mentais demandam monitoramento e gerenciamento de longo prazo. Em relação às incapacidades causadas, a depressão é preocupante porque se estima que até 2020 ela só seja superada pelas doenças cardíacas. Nesse sentido, os impactos pessoais, sociais e econômicos causados pela depressão serão significativos. Há também uma indicação de que os transtornos mentais representavam 9\% das enfermidades crônicas nos países em desenvolvimento, como o Brasil, e uma estimativa de aumento para 14\%, em 2020.

Observa-se, portanto, que a incorporação das ações de saúde mental na atenção básica é uma prioridade no cenário atual. Porém, não é algo que se efetiva sem o desenvolvimento de estratégias institucionais como capacitações, supervisões, financiamento, dentre outras. Nesse sentido, o Ministério da Saúde propôs a estratégia do Apoio Matricial (AM) para facilitar o direcionamento dos fluxos na rede, promovendo uma articulação entre os equipamentos de saúde mental e as Unidades Básicas de Saúde (UBS). Segundo a coordenação de Saúde Mental, no documento apresentado à Conferência Regional de Reforma dos Serviços de Saúde Mental, o AM se constitui em:

Um arranjo organizacional que viabiliza o suporte técnico em áreas específicas para equipes responsáveis pelo desenvolvimento de ações básicas de saúde. Nesse arranjo, a equipe de saúde mental compartilha alguns casos com as equipes de Atenção Básica. Esse compartilhamento se produz em forma de corresponsabilização pelos casos, que podem se efetivar através de discussões conjuntas de casos, intervenções conjuntas junto às famílias e comunidades ou em atendimentos conjuntos, e também na forma de supervisão e capacitação (Brasil, 2005, p. 34).

Em outras palavras, o Apoio Matricial surgiu a partir da constatação de que a reforma psiquiátrica não pode avançar se a atenção básica não for incorporada ao processo. Não é viável concentrar esforços somente na rede substitutiva, mas é preciso estender o cuidado em saúde mental para todos os níveis de assistência, em especial, à atenção primária. Entretanto, sabemos que as equipes de atenção básica se sentem desprotegidas, sem capacidade de enfrentar as demandas em saúde mental que chegam cotidianamente ao serviço, especialmente os casos mais graves e/ou crônicos. 0 matriciamento visa dar suporte técnico a essas equipes, bem como estabelecer a corresponsabilização.

Ao ser entendido como uma metodologia de trabalho que visa assegurar retaguarda especializada, tanto em nível assistencial quanto técnico-pedagógico, pressupõe assim uma construção compartilhada entre a equipe de referência, composta de profissionais da atenção básica, que têm a responsabilidade pela condução de um caso individual, familiar ou comunitário, e os apoiadores, que são especialistas com a missão de agregar conhecimentos à equipe de referência, contribuindo com intervenções que aumentem sua capacidade de resolver problemas (Campos e Domitti, 2007).

Essa articulação cria a possibilidade de efetivar a tão almejada clínica ampliada, cuja função, por excelência, seria acompanhar movimentos, metamorfoses subjetivas, paisagens que vão se processando cotidianamente na vida, proporcionando um meio criador para encontros e composições. Uma clínica como prática política que tem a ver com afeto e com a fabricação de modos de existência. Entretanto, muitas são as dificuldades para a efetivação dessa proposta. A lógica capitalista, o individualismo, a competitividade e a segregação tão evidentes nas sociedades atuais, contrapõem-se à lógica do trabalho em equipe, à corresponsabilização e à escuta qualificada, práticas essenciais para a execução da proposta do Apoio Matricial $^{2}$.

Segundo o Relatório da gestão 2003/2006 do Ministério da Saúde (Brasil, 2007), a estratégia de implementação de Equipes Matriciais de Referência em Saúde Mental está sendo articulada junto aos gestores, e cada vez mais os municípios têm aderido a essa proposta. Com a institucionalização da Estratégia Saúde da Família na maior parte do país, a atenção básica foi instigada a produzir invenções para desenvolver a integralidade da atenção com grupos de saúde mental egressos de longas internações psiquiátricas.

2 GOMES, V. G. Apoio matricial: estratégia de interlocução na rede de saúde de Campinas/SP. 2oo6. Trabalho de Conclusão de Curso (Aprimoramento em Saúde Mental) - Faculdade de Ciências Médicas da Unicamp, Campinas, 2006. 
O Apoio Matricial às equipes da atenção básica deve partir dos CAPS, pois estes são serviços que ocupam lugar central na proposta da reforma psiquiátrica, sendo seus dispositivos por excelência. São considerados ordenadores da rede de saúde mental, direcionando o fluxo e servindo de retaguarda para as residências terapêuticas, bem como para a atenção básica. Para isso, mecanismos de indução financeira pelo Ministério da Saúde para o desenvolvimento da política de saúde mental na atenção básica são fundamentais. É necessário melhorar a articulação desses serviços com atenção básica para que as equipes dos CAPS se desloquem de espaços tradicionalmente institucionalizados e passem a realizar um trabalho em conjunto com as equipes da atenção básica, que pela proximidade com as famílias e as comunidades, são essenciais para garantir o acesso e o enfrentamento de agravos vinculados ao uso abusivo de álcool, outras drogas e diversas formas de sofrimento psíquico.

As experiências das equipes matriciais de saúde mental e os processos de formação estão ainda em construção. Não há dúvida de que a implantação, expansão e qualificação do apoio matricial são grandes desafios para a gestão da Política de Saúde Mental do país nos próximos anos e a garantia de acessibilidade à atenção, um dos maiores desafios do Sistema Único de Saúde. Do mesmo modo, o fortalecimento de uma política efetiva de formação continuada que envolva tanto as equipes de saúde mental quanto as da atenção básica deverá ser uma das principais prioridades, objetivando, com isso, minimizar a fragmentação da assistência em saúde tradicional.

Em Natal, RN, desde 2006, está ocorrendo um processo de implementação do AMl, articulando a rede de serviços substitutivos e Unidades Básicas de Saúde da Família. As discussões acerca do AM em Natal estão em fase inicial, avançando significativamente. Esse projeto está em curso em parte da rede, tendo sido iniciado pelas Unidades de Saúde da Família. São apoiadas pelos CAPS atualmente duas unidades no Distrito Sanitário Oeste, três unidades no Distrito Sanitário Leste e uma no Distrito Norte I. Está previsto mais de 30\% de unidades apoiadas até o fim de 2008 (Prefeitura Municipal de Natal, 2006). A Coordenação em Saúde Mental do município pretende com o Apoio Matricial a ampliação da rede em saúde mental, a capacitação dos profissionais envolvidos e a garantia de acesso para todos os usuários que necessitem de atenção em saúde mental.

Nesse contexto, buscou-se conhecer o processo local e discutir seu funcionamento com técnicos de equipes de PSF que estão participando atualmente da proposta de matriciamento.

\section{Metodologia}

Para realizar essa investigação optou-se por trabalhar com técnicos vinculados às Unidades de Saúde da Família do Distrito Sanitário Leste, região eleita pela Secretaria Municipal de Saúde (SMS) para dar início ao processo de discussão e implementação do AM. Além disso, essa região concentra o maior número de serviços substitutivos em SM no município. As USF do Distrito Leste estão assim distribuídas: USF Guarita (duas equipes), USF Passo da Pátria (duas equipes) e USF Rocas (quatro equipes), totalizando 8 equipes. Realizamos entrevistas, a partir de um roteiro semiestruturado de questões, com um técnico de nível superior e o coordenador de cada uma das equipes, sendo cinco médicos e três dentistas, e apenas seis coordenadoras de Equipes de Saúde da Família - todas enfermeiras - totalizando 14 entrevistas. Neste trabalho, apresentamos os resultados das entrevistas com os oito técnicos. Todas foram gravadas após consentimento dos participantes. No caso em que não houve concordância no uso desse instrumento, a entrevista foi anotada. As questões visavam conhecer a avaliação de cada técnico acerca da proposta de implantação do AM, sua participação nesse processo, as estratégias que vêm sendo utilizadas, o que já avançou, as dificuldades, a importância deste arranjo para a rede de saúde e sugestões para a continuidade do processo. Mais especificamente, buscamos conhecer o tipo de demanda em saúde mental recebida, os modos de acolhimento e referenciamento produzidos e as habilidades requeridas para isso.

\section{Resultados e Análise}

\section{Tipo de Demanda em Saúde Mental Vivenciada no Cotidiano}

De um modo geral, a demanda relativa à saúde mental mais frequente na realidade das USF é a de pacientes que procuram a unidade para renovar a receita e continuar o tratamento. 
Aparece demanda, paciente com queixa depressiva como hoje apareceu uma, que sofre angústia por perda de algum parente, paciente que faz uso crônico de medicação controlada, a gente tem também aqui, muitos pacientes que já vem usando medicamento há um tempo prescrito por um psiquiatra. (Médica)

Outras demandas também foram mencionadas, como uso de álcool e drogas e situações constatadas como sendo transtorno mental na área de cobertura da equipe. Contudo, a demanda pela renovação de receitas parece ser mais comum e mais alarmante.

O modo de acolhimento da demanda em saúde mental expresso nas entrevistas indica o privilegiamento dos cuidados medicamentosos e especializados para a resolução dos problemas de saúde na população. Nas ESF pesquisadas isso se reflete de duas maneiras: o encaminhamento da demanda em saúde mental aos serviços/profissionais especializados e a prescrição de receitas psiquiátricas.

O medicamento é visto como a principal prática terapêutica na rede pública de saúde, sendo muitas vezes considerado o único recurso disponível para aqueles que necessitam desse tipo de cuidado, tornando os usuários dependentes. Esse fenômeno, de acordo com Carvalho e Dimenstein (2004), está relacionado ao papel privilegiado da indústria farmacêutica na atenção à saúde e à força do modelo biomédico, ainda hegemônico nas práticas de saúde. De acordo com esses autores:

O fenômeno da medicalização, apesar de não ser um problema atual [...] está muito presente nos dias de hoje e ocupa um lugar importante no jogo de interesses do poder econômico. O consumo de medicamentos tem um significativo impacto na sociedade, haja vista constituir o principal meio de combate à doença na prática terapêutica atual e também por ter relevante significância em termos econômicos. Aliado a isso, existe o fato de as consultas médicas resultarem quase sempre numa prescrição, decorrente de uma visão limitada da saúde, para a qual o medicamento tornou-se a principal ferramenta (p. 122).

Por conseguinte, deixa-se de ter uma visão ampla dos problemas e de seus determinantes, resultando numa crença generalizada de que não parece ser pos- sível enfrentar os problemas de saúde sem a presença do arsenal terapêutico oferecido pelo sistema médico-industrial. Com isso, o medicamento passa a estar vinculado ao bem-estar ou mesmo à felicidade.

\section{Ações em Saúde Mental Realizadas nas USF}

Diante da demanda apresentada nas USF, os técnicos entrevistados, em geral, renovam as receitas psiquiátricas sem maiores questionamentos sobre essa estratégia de intervenção.

A gente recebe, mas geralmente se resume a paciente que já é acompanhado por um psiquiatra e vem apenas para a gente transcrever a receita [...] nós não temos condições de dar um suporte terapêutico, diagnóstico em saúde mental, que é uma coisa muito especializada. (Médica)

É possível perceber que a concepção de ações em saúde está bastante compartimentalizada, com intervenções fragmentadas por especiliadades. A crescente fragmentação pela qual a medicina e outras áreas da saúde passaram, levando à formação de áreas de conhecimentos distintas e com objetos de intervenção diferenciados, dificultam pensar ações integrais em saúde que privilegiem a concretude da vida dos sujeitos (Campos e Domitti, 2007).

Mas assim, isso é a minha realidade, mas as médicas do posto geralmente encaminham para um especialista, porque elas não podem ficar prescrevendo esses medicamentos, né? Então tem que realmente encaminhar para um especialista. $\varepsilon$ aí elas têm feito isso. (Dentista)

A visão predominantemente fragmentada do trabalho em saúde, baseada nos conhecimentos especializados, propicia ainda o fortalecimento da lógica do encaminhamento. Campos e Domitti (2007) apontam que o apoio matricial vem tentar reverter essa lógica de encaminhamento, pois essas intervenções pressupõem sempre uma lógica de hierarquização, havendo uma diferença de poder/saber entre quem encaminha e quem recebe e ainda uma transferência de responsabilidade. A partir das entrevistas, percebe-se que isso propicia e reforça a impotência desses técnicos diante da demanda em saúde mental apresentada na unidade, além da cristalização das tradicionais intervenções em saúde mental, e na saúde global, de prescrição de medicamentos e encaminhamentos. Entretanto, muitas ações podem ser 
desenvolvidas em parceria com os técnicos do CAPS, tais como: consulta/atendimento, trabalhos em grupo, visita domicilar, reuniões com a equipe etc.

\section{Definição da Proposta do Apoio Matricial}

Em relação às equipes de PSF, foi possível constatar que a proposta do AM ainda não está clara para esses profissionais. Ainda há muitas incertezas e expectativas equivocadas por parte de alguns técnicos. A maioria dos profissionais sequer foi capaz de definir a proposta indicando seus pontos mais importantes. As escassas definições identificaram o AM como uma estratégia de descentralização no atendimento em saúde mental, como forma de orientação para o atendimento, incluindo a questão dos medicamentos. Uma das entrevistadas o percebe como uma espécie de suporte emocional para os técnicos de PSF. Apesar da pouca informação se justificar, em parte, pelo fato de as entrevistas terem sido realizadas em um estágio inicial do processo - apenas algumas reuniões iniciais haviam ocorrido -, ainda sim é preocupante. Uma proposta como essa, que envolve muitos atores em sua elaboração e execução, deve ser discutida por todos os envolvidos, visto que as ações deverão ser construídas em parceria no decorrer do processo. Não se trata, portanto, apenas de tomada de decisões no nível da gestão, de forma centralizada e isolada, mas de forma compartilhada e pactuada.

\section{Importância do Apoio Matricial para as Equipes de PSF}

Então na prática se objetiva que a gente lide melhor com essa demanda porque serviços especializados não dão conta, então eles querem que o PSF inclua um trabalho em saúde mental. (Médica)

Diante disso, todos os técnicos entrevistados relataram a necessidade de ter um suporte para o acolhimento em saúde mental, contudo há maneiras distintas de concepção: alguns mencionaram que a contribuição do AM às equipes poderia se realizar por meio da oferta de capacitações, treinamentos, palestras, na área específica; outros mencionaram a importância da presença de um psicólogo por Unidade Básica de Saúde, bem como de um veículo para o transporte de usuários; outro mencionou a importância de suporte emocional para os técnicos. A perspectiva de um atendimento efetivo para a demanda em saúde mental na unidade básica é vislumbrada; entretanto a possibilidade de um trabalho articulado entre USF e o serviço especializado não é percebida. Tradicionalmente, o modelo hierarquizado de atendimento em saúde produziu fragmentação e burocratização nas formas de relacionamento entre os serviços de saúde, instituindo formas de se conceber e de se intervir nos equipamentos de saúde, repercutindo na desresponsabilização em vez de corresponsabilização entre profissionais e serviços. Dessa forma, o cuidado com a demanda em saúde mental é visto como um acréscimo de trabalho e encarado como uma desresponsabilização dos serviços especializados.

Entretanto, a proposta do AM é articular atenção básica e serviço especializado, promovendo encontros de saberes que proporcionem uma atuação mais integral e menos fragmentada. Dessa forma, o CAPS, no papel de serviço especializado, não estaria desresponsabilizando-se de sua demanda, mas passando a atuar numa outra perspectiva, a de descentralizar esse cuidado, levando-o para mais perto do usuário. Os profissionais desse serviço estariam orientando e construindo, juntamente com os profissionais da atenção básica, um novo modelo de atenção, em que o maior beneficiado é o próprio usuário. Não há, portanto, um desvio e sim um compartilhamento de responsabilidades. Campos (1999) aponta um novo sistema de referência entre profissionais e usuários para a efetivação da proposta de Apoio Matricial em que:

A tradicional noção de referência e contra-referência vigente nos sistemas de saúde: quando um paciente se utiliza de um serviço matricial ele nunca deixa de ser cliente da equipe de referência. Neste sentido, não há encaminhamento, mas desenho de projetos terapêuticos que não são executados apenas pela equipe de referência, mas por um conjunto mais amplo de trabalhadores. De qualquer forma, a responsabilidade principal pela condução do caso continua com a equipe de referência (p. 396).

A proposta de AM faz-se a partir do desenho de um projeto terapêutico integrado entre a equipe de referência da atenção básica e a equipe de outros serviços adequados à demanda de cada caso. Nesse sentido, as intervenções seriam complementares umas às outras, de modo que os projetos terapêuticos fossem enriquecidos, utilizando-se do compartilhamento dos saberes específicos dos diversos profissionais de saúde. Além disso, a proposta do AM busca o funcionamento efetivo da rede, em que os CAPS deveriam atuar, no 
caso da Saúde Mental, como articulador estratégico, trabalhando em conjunto com as Unidades Básicas e com outros setores, sejam serviços de saúde ou outros recursos comunitários, ou seja, trata-se de mudanças de práticas e por isso produzem resistências tanto nas equipes de atenção básica quanto nas de serviços especializados.

\section{Estratégias de Implementação pela Secretaria Municipal de Saúde}

As estratégias já em andamento, apontadas pelos profissionais do PSF, foram as reuniões realizadas nas unidades com a equipe da coordenação de saúde mental, com a supervisora territorial e com profissionais dos CAPS. A participação dos profissionais da rede básica no processo de implantação do AM, no momento da entrevista, restringiu-se apenas à participação na reunião, visto que as entrevistas se deram em um momento inicial, particularmente para esses profissionais que não haviam participado de qualquer discussão anterior e, em muitos casos, estavam tomando conhecimento do assunto muito recentemente. Como estratégias para continuidade do processo, a maioria dos entrevistados considerou que era cedo para definir. Contudo, apontaram alguns aspectos que devem ser levados em consideração: o fato de a presença das equipes de saúde mental na UBS ser muito positiva, pois elas passam a conhecer a realidade da unidade e formular intervenções sintonizadas; o processo deve se dar por meio de uma construção coletiva entre os diferentes atores envolvidos, ou seja, os passos e estratégias devem ser traçados em conjunto para que sejam operacionalizáveis. Nesse sentido, Campos (1999) destaca que:

0 reconhecimento da necessidade de eventual comunicação entre as distintas profissões que operam nos serviços de saúde representa um avanço, um início de enfretamento do problema, mas apenas com discurso não é alterada a estrutura que reforça esta separação. Na lógica da integração episódica, eventuais encontros horizontais tentariam amainar estes conflitos e desacertos (p. 399).

É necessário construir projetos terapêuticos que privilegiem a intervenção conjunta de vários recursos e especialidades em saúde. A proposta do AM, segundo Campos e Domitti (2007), aponta exatamente a construção de estratégias integradas entre a equipe de referência da Unidade Básica e a equipe apoiadora.
Isso permite a construção coletiva de práticas de intervenção, explorando os diversos saberes sobre os casos apresentados, privilegiando a corresponsabilização.

\section{Avaliação da Proposta}

Apesar de não estar totalmente clara a proposta do AM, os técnicos da Estratégia de Saúde da Família avaliaram-na como positiva pelo fato de promover a aproximação da atenção básica com a especializada. Os profissionais parecem vislumbrar no AM um catalisador de suas angústias em lidar com uma demanda que lhes chega cotidianamente, mas para qual não se sentem preparados.

Eu acho interessante porque é um canal que eles têm para ouvir também a gente [...] porque eles estão vendo que na prática não é tão fácil jogar a demanda de saúde mental para a equipe de PSF sem preparo, porque na prática a gente não vai ter capacitação para atender e o próprio doente não vai querer. (Médica)

Faz parte do imaginário social contemporâneo acreditar que a grande especialização profissional, em especial a médica, é a estratégia mais eficiente para se cuidar da saúde. Sendo assim, os profissionais dessa área vão cada vez mais restringindo seu campo de atuação, ao mesmo tempo em que a população em geral também vai incorporando esses valores e passando a acreditar somente na atuação de um especialista. Nesse sentido, os técnicos em saúde mental terão como tarefa, além de atuar como apoiadores, desmistificar a ideia de que só os especialismos trazem resolutividade. Pelo contrário, tem se trabalhado na perspectiva de que só a integralidade é realmente efetiva na promoção da saúde.

\section{Dificuldades em Relação à Implementação da Proposta do AM}

Muitos consideraram cedo para traçar maiores considerações acerca das dificuldades. No entanto, alguns pontos foram mencionados. A maior dificuldade citada para implementação do AM foi a falta de conhecimentos específicos em saúde mental por parte desses profissionais, cuja formação é generalista ou com especialidades em outras áreas. Essa parece ser, para eles, a maior dificuldade, não apenas em relação à implementação do AM, mas em relação ao cotidiano das demandas de SM. Essa dificuldade, porém, não se 
coloca como um entrave definitivo, desde que tenham suporte e orientação adequados.

Outras dificuldades relacionaram-se às greves recentes que paralisaram o processo e à estrutura física precária de algumas Unidades Básicas de Saúde. Segundo os entrevistados não há articulação entre os serviços da rede básica e especializada, salvo quando se trata de alguns encaminhamentos, partindo deles para os serviços especializados. Quando acontece esse referenciamento não há acompanhamento do caso, nem retorno por parte do serviço especializado. Alguns entrevistados apontaram, ainda, que o AM pode fortalecer essa articulação, que é um dos objetivos da proposta do AM, possibilitando uma mudança no sistema de referência vigente até então. Isso se efetivaria através do agendamento contínuo de reuniões e de contatos através de outros meios de comunicação, via telefone ou meio eletrônico.

\section{Considerações Finais}

Os eixos de discussão citados apontam a predominância do paradigma biomédico na atenção à saúde, em que se privilegiam os cuidados medicamentosos na resolução dos problemas de saúde da população, como a prescrição indiscriminada de psicotrópicos. A visão predominantemente fragmentada do trabalho em saúde, por sua vez, ancorada nos conhecimentos especializados, propicia ainda o fortalecimento da lógica do encaminhamento. A perspectiva de um atendimento efetivo para as demandas em saúde mental na unidade básica é vislumbrada como necessária, entretanto, um trabalho articulado entre essa instituição e o serviço especializado não é percebido ainda. Isso acontece porque, tradicionalmente, o modelo hierarquizado de atendimento em saúde produziu uma fragmentação e burocratização na formas de relacionamento entre os serviços, instituindo formas de se conceber e de se intervir, acarretando uma desresponsabilização em detrimento da corresponsabilização entre profissionais e serviços de saúde. É justamente essa tendência que a estratégia do Apoio Matricial visa superar.

Essa realidade, no entanto, não é privilégio do município de Natal. Campos e Domitti (2007) apontam uma lógica de extrema fragmentação do cuidado e para a estrutura que cria dificuldades gerenciais extremas à adoção do método de trabalho do Apoio Matricial, como sendo uma dificuldade presente no SUS como um todo. A relação pontual e fragmentada entre profissional/paciente predominante nos serviços de saúde; os atendimentos que são realizados para atender uma queixa específica, sem um prosseguimento horizontal de projetos terapêuticos, os quais, por sua vez, são reduzidos “à dimensão médica e, em geral, com exagerado enfoque biológico e individual, impondo uma redução do terapêutico ao uso de medicamentos, procedimentos cirúrgicos" (Campos, 1999, p. 402), tudo isso dificulta a implementação do AM. Esse quadro se agrava ainda mais quando nos voltamos para discussões específicas do campo da reforma psiquiátrica, pois saímos dos momentos épicos e entramos em tempos problemáticos.

Isso quer dizer que enfrentamos atualmente o desafio não só de avançar nas conquistas já alcançadas, tais como a redução considerável do número de leitos psiquiátricos e a inversão dos gastos públicos destinados ao pagamento de internações psiquiátricas, a predominância da oferta de cuidados extra-hospitalares, expansão da rede de serviços substitutivos e a existência de um vasto cenário epistemológico para pensar a saúde mental não mais fixado no reducionismo biológico (Delgado, 2007), mas enfrentar os obstáculos que se apresentam no cenário atual da reforma e que afetam sua sustentabilidade.

Esses obstáculos são de diversas ordens. Podemos elencar num primeiro nível aspectos como: a necessidade de redimensionamento do financiamento do modelo; a ampliação das equipes e capacitação técnica; o desenvolvimento de mecanismos de avaliação dos serviços; a incorporação das ações de saúde mental na atenção básica etc. Essa ordem tem sido privilegiada ao longo dos últimos anos sem uma problematização acerca dos seus limites, da obsessão pela burocracia, da trama das pequenas relações do dia-a-dia, que dificultam a transformação/avanço das práticas em saúde mental, ou seja, há outra ordem de desafios que implica na problematização da própria condução da reforma, dos princípios moralizantes que norteiam as práticas; do cotidiano repetitivo e banalizado; da acomodação e burocratização da vida; das relações de poder/saber e preocupações utilitaristas por parte dos técnicos; da motivação emancipatória identificada à normatização, à medicalização. Quais as consequências de se focar somente nesse primeiro nível de questões? Primeiramente, passamos a viver a crença de que se alcançou o 
"lugar desejado" ou que a reforma está garantida com a simples existência de serviços substitutivos; a produção de um tipo de cuidado pouco diversificado - modelo ambulatorial dominante, e de novas cronicidades em relação aos usuários, profissionais e dispositivos em saúde mental tal como aponta Barros (2003). Essas cronicidades se expressam quando não operamos rupturas na lógica manicomial, quando não interferimos na política de subjetivação vigente, que exclui a "loucura” e discrimina o "louco"; nos modos de gestão autoritários, pouco participativos e desconectados de uma perspectiva crítica e política de trabalho; nos especialismos que produzem práticas empobrecidas e pouco potentes em produzir efeitos desinstitucionalizantes nas vidas de usuários, familiares e dos próprios técnicos, enfim, reproduzimos nos serviços substitutivos, nas relações cotidianas, muito daquilo que queremos desmontar nas instituições psiquiátricas.

Essa situação tem sido identificada na forma como os CAPS têm operado. No funcionamento de alguns deles observa-se um modus operandi ambulatorial, centrado no trabalho individualizado de diferentes técnicos, com pouca inserção no território, o que dificulta a produção de trocas entre os diferentes atores sociais e com a rede de saúde. Relações hierarquizadas entre usuários/técnicos, técnicos/familiares e entre os próprios técnicos, oficinas como meros dispositivos de ocupação do tempo, sendo mais uma tarefa a ser cumprida, cheia de regras rígidas, havendo pouco espaço para a criação, tudo isso faz parte da rotina do serviço. 0 acolhimento é o momento de transmitir valores para o usuário como a forma mais adequada de ser e agir (formas de existência idealizadas). Há, na verdade, muita disciplina, práticas de vigilância/ameaça (se não seguir as regras está fora do serviço, volta para o hospital, perde a vaga no CAPS), visando à domesticação da "loucura". O medicamento ocupa posição privilegiada no tratamento e estar bem é entendido como remissão de sintomas. Por fim, nota-se um trabalho voltado para si próprio, não havendo interface com a cidade, e sua existência não produz nenhum efeito no território.
Outro ponto crítico diz respeito à presença de um quantitativo enorme de usuários crônicos nos hospitais, bem como a re-internação sucessiva, fatos bastante evidentes no contexto atual da atenção em saúde mental. Estima-se que, hoje, no país, de $25 \%$ a $30 \%$ do total dos leitos são ocupados por portadores de transtornos mentais crônicos (Brasil, 2007). Isso representa um contingente enorme de pessoas moradoras dessas instituições que podem se beneficiar com a estratégia do Programa de Volta para Casa ${ }^{3}$ e das Residências Terapêuticas ${ }^{4}$. Em Natal, no Hospital Dr. João Machado, 63,09\% das internações registradas de janeiro a julho de 2007 são reincidências 5 . Essas constantes re-internações, em geral, são decorrentes da inexistência ou ineficácia de uma rede de suporte e atenção extra-hospitalar, da ausência de tratamento e esclarecimento sobre a necessidade de acompanhamento continuado, conflitos familiares, comorbidade com drogas, determinação judicial, tratamento e uso irregular de medicação, desinformação sobre os transtornos mentais e problemas decorrentes do imaginário, que associa o louco à periculosidade, marginalidade $\mathrm{e}$ agressividade, gerando intolerância e violência para com o sujeito em sofrimento mental. Muitos desses aspectos podem ser abordados pelas equipes de saúde da família integrando-os às atividades que desenvolvem via proposta do acompanhamento terapêutico (AT), por exemplo, ou seja, tanto os usuários crônicos quanto os que registram várias re-internações podem se beneficiar de uma articulação mais próxima entre atenção básica e saúde mental, passando a ter uma atenção continuada por diversas formas de ação promovidas em parceria.

Experimentar inovações, construir interfaces, uma "zona de comunidade" (Teixeira, 2004) entre saúde mental e atenção básica parece ser uma via privilegiada de mudança daquilo que hoje nos parece pouco resolutivo e estagnado. Esses movimentos implicam em operar lutas transversais, como alerta Alarcon (2002), por meio de intensas problematizações do cotidiano, articulando o que é da ordem das condições políticas

\footnotetext{
3 Brasil. Ministério da Saúde. Manual do Programa “De Volta Para Casa”. Brasília, dezembro de 20o3. Disponível em: <http:// portal.saude.gov.br/portal/arquivo/pdf/Manual\%2odo\%2oPrograma\%2oDe\%2oVolta\%2oPara\%2oCasa_dez2oo3.pdf>.

4 Disponível em: <http://portal.saude.gov.br/portal/saude/visualizar_texto.cfm?idtxt=29803\&janela=1>.

5 Município Internações Fonte: Ministério da Saúde - Sistema de Informações Hospitalares do SUS (SIH/SUS). Consulte o site da Secretaria Estadual de Saúde para mais informações.
} 
e sociais da atualidade com aspectos micropolíticos, com as forças que geram esse produto que queremos combater: o personagem doente mental, a exclusão social, o medo, o imobilismo, a violência contra o "louco" etc.

As iniciativas de reestruturação da assistência psiquiátrica hospitalar e a construção de uma rede de atenção de base comunitária, em que o matriciamento se apresenta como uma das possíveis estratégias, têm a potencialidade de nos fazer confrontrar com aquilo que. segundo Mattos (2006), se constitui um traço presente ao longo dos séculos em relação à "loucura": o silêncio cúmplice dos observadores. Sangrias, hidroterapia, castigos físicos, coma insulínico, eletrochoque, lobotomia, muitas e variadas técnicas foram experimentadas desde a antiguidade até os psicofármacos desenvolvidos após a Segunda Guerra Mundial e que hoje ocupam posição privilegiada no tratamento dos transtornos mentais. Essas técnicas foram largamente utilizadas e ainda estão em uso, como é o caso do eletrochoque, causando danos irreversíveis e a morte de muitas pessoas no mundo inteiro. Técnicas produzidas a partir de um "saber científico" sobre a "loucura", que visava sua correção e aniquilamento, sustentadas pelo silêncio sufocante, temeroso, torturado, repugnante, dos observadores, experts, cientistas, técnicos adestrados e investidos de poder. Atualmente, a hegemonia inconteste racionalidade técnico-científica ocidental produz novos e mais sofisticados mecanismos de controle, mas o silêncio se mantém, atravessando as práticas agora revestidas de tolerância. 0 equilíbrio dos medos permanece intocado, a cultura da obediência não cessa de proliferar.

A possibilidade de cuidado e escuta fora do modelo manicomial só é realizável com o enfrentamento desse silêncio, que atravessa os tempos e a geografia e é da ordem dos afetos. Fazer uma estratégia institucional acontecer como o apoio matricial é lidar com uma ordem de cronicidade, com uma lógica modelar presente nos modos de subjetivação hegemônicos na contemporaneidade, que nos faz cada vez mais silenciosos, obedientes, dóceis, conformistas, ou seja, é empreender uma guerra contra uma política de subjetivação que exige consensos, razoabilidade, o exorcismo do disparatado, e em contrapartida promete segurança, bem-estar, pacificação, conforto, operando pela via do medo e da esperança. Como diz Tótora
(2005), inspirada em Nietzsche, "a esperança e o medo são paixões daqueles que necessitam de crenças que lhes dê um sentido para sua existência. A esperança de uma existência segura, de bem-estar, é a promessa que atrai homens cansados" (p. 87).

A fragmentação das práticas e saberes em saúde, bem como as dificuldades vividas pelos coletivos de trabalho em seu enfrentamento cotidiano está intimamente relacionada ao medo de aventurar-se em direção a algo que abale os valores vigentes, que produza instabilidade. 0 corporativismo é um desses alvos. Geralmente, atribuímos responsabilidade e culpa às relações de poder, às hierarquias profissionais, à falta de capacitação e remuneração adequadas, à má gestão, ao imobilismo das práticas no campo da saúde. Entretanto, é raro nos questionarmos sobre o que não queremos mudar, sobre pactos, sobre as ideias de que as coisas e pessoas são como são e não podem mudar, que a nossa vida está na única possibilidade que teria, sobre tudo aquilo que ao vir a ser alterado nos fará sentir demais, trabalhar mais, se expor demais, sofrer mais, sobre situações que nos lançam em confrontos diários e exigem posicionamento ético. Não vamos nos iludir, há muita servidão em nós. "Essa cosmovisão fatalista expressa uma geografia da conformidade e o aprisionamento no território da subserviência e, claro, da insignificância em relação à possibilidade de construir uma realidade que seja diferente" (Cortella, 2005, p. 171). Assim, perguntamos: o que faríamos se não tivéssemos tanto medo?

Na articulação saúde mental/atenção básica, estamos diante da necessidade de inventar uma atuação transdisciplinar de agenciamento social em que, "resistir deve ser algo mais que simplesmente inviabilizar a existência dos manicômios" (Alarcon, 2002, p. 117); mas pôr algo de infame no ar, invadindo as narinas, algo insuportável no culto da tolerância. Como diz Oliveira (2005), aos insubordináveis resta arruinar essa tolerância, pois “o resto é perfumaria” (p. 201).

\section{Referências}

ALARCON, S. Nos limites da desmesura: aforismos sobre Reforma Psiquiátrica e Movimento Antimanicomial no Brasil. 2002. Dissertação (Mestrado em Saúde Pública) - Escola Nacional de Saúde Pública da Fundação Oswaldo Cruz, Rio de Janeiro, 2002. 
BARROS, R. B. de. Reforma Psiquiátrica Brasileira: resistências e capturas em tempos neoliberais. In: CONSELHO FEDERAL DE PSICOLOGIA. Loucura, ética e política: escritos militantes. São Paulo: Casa do Psicólogo, 2003. p. 196-206.

BRASIL. Ministério da Saúde. Secretaria de Atenção à Saúde. DAPE. Coordenação Geral de Saúde Mental. Reforma psiquiátrica e política de saúde mental no Brasil. Brasília, DF: OPAS, 2005. Documento apresentado à Conferência Regional de Reforma dos Serviços de Saúde Mental: 15 anos depois de Caracas.

BRASIL. Ministério da Saúde. Secretaria de Atenção à Saúde/DAPE. Saúde Mental no SUS: acesso ao tratamento e mudança do modelo de atenção: relatório de gestão 2003-2006. Brasília, DF, 2007.

CAMPOS, G. W. de S. Equipes de referência e apoio especializado matricial: um ensaio sobre a reorganização do trabalho em saúde. Ciência e Saúde Coletiva, Rio de Janeiro, v. 4, n. 2, p. 393-403, 1999.

CAMPOS, G. W. S.; DOMITTI, A. C. Apoio matricial e equipe de referência: uma

metodologia para gestão do trabalho interdisciplinar em saúde. Cadernos de Saúde Pública, Rio de Janeiro, v. 23, n. 2, p. 399-407, 2007.

CARVALHO, L. de F.; DIMENSTEIN, M. O modelo de atenção à saúde e o uso

de ansiolíticos entre mulheres. Estudos de Psicologia, Natal, v. 9, n. 1, p. 121-129, 2004.

CORTELLA, M. S. Recusar a destruição da convivência digna! (valores inadiáveis). In: PASSETTI, E.; OLIVEIRA, S. (Org.). A tolerância e o intempestivo. Cotia: Ateliê, 2005. p. 169-176.
DELGADO, P. G. O otimismo da prática em tempos de mudança: clínica e política no novo cenário da reforma psiquiátrica. In: RIBEIRO, M. A. T.; BERNARDES, J. S.; LANG, C. E. (Org.). A produção na diversidade: compromissos éticos e políticos em psicologia. São Paulo: Casa do Psicólogo, 2007. p. 197-206.

MATTOS, V. Crime e psiquiatria: preliminares para a desconstrução das medidas de segurança. Rio de Janeiro: Revan, 2006.

OLIVEIRA, S. Tolerar, julgar, abolir. In: PASSETTI, E.; OLIVEIRA, S. (Org.), A tolerância e o intempestivo. Cotia: Ateliê, 2005. p. 191-202.

OMS - ORGANIZAÇÃO MUNDIAL DA SAÚDE. Cuidados inovadores para condições crônicas: componentes estruturais de ação. Brasília, DF, 2003.

PREFEITURA MUNICIPAL DE NATAL. Secretaria Municipal de Saúde. Relatório anual de gestão. Natal, 2006.

ROSA, L. Transtorno mental e o cuidado na família. São Paulo: Cortez, 2003.

Teixeira, R. R. As redes de trabalho afetivo e a contribuição da saúde para a emergência de uma outra concepção de público. San Diego: University of California, 2004. Working-paper apresentado na Research Conference on: Rethinking "the Public" in Public Health: Neoliberalism, Structural Violence, and Epidemics of Inequality in Latin América. Disponível em: <http://www.corposem.org/rizoma/ redeafetiva.htm>. Acesso em: o1 jul. 2007.

TÓTORA, S. (In)tolerância: vida-poiesis e política. In: PASSETTI, E.; OLIVEIRA, S. (Org.). A tolerância e o intempestivo. Cotia: Ateliê, 2005. p. 75-92. 